\title{
Fabrication and characterization of chitosan coated human hair reinforced phytagel modified soy protein-based green composite
}

\author{
${ }^{1}$ Department of Mechanical Engineering, G. B. Pant University of Agriculture and Technology, Pantnagar, India, E-mail: \\ namanjainyati@gmail.com
}

\begin{abstract}
:
In the present investigation, human hair reinforced soy protein isolate (SPI)-based green composites modified with $40 \mathrm{wt}$ \% phytagel and $12.5 \mathrm{wt}$ \% glycerol were developed. Characterization of the prepared composites was done through water absorption, tensile test, scanning electron microscopy (SEM) and dynamic mechanical analysis (DMA). Composites having $2 \mathrm{wt}$ \% of human hair fiber gave the optimum results for the tensile test. At $2 \mathrm{wt} . \%$ of human hair composition maximum tensile strength $17.23 \mathrm{MPa}$ was obtained whereas the tensile strength of neat SPI was 8.54 MPa. SEM images show the interfacial bonding between human hair fiber and SPI resin and gave the clear explanation of the change in tensile strength and water absorption \%. Chitosan coating was applied to fabricated composites to reduce water uptake. Chitosan coated sample showed considerable improvement in tensile strength, water uptake and glass transition temperature.
\end{abstract}

Keywords: coating, DMA, green composites, human hair, soy protein

DOI: $10.1515 / j m b m-2018-0007$

\section{Introduction}

In today's evolving world there is an increasing demand for materials which have a remarkable combination of properties that cannot be gotten from metals, polymers, etc. so scientists are turning their attention toward composites. Green composites have numerous applications in the automobile, aerospace and underwater sectors. Composites are multiphase resources that contain chemically dissimilar elements that have a discrete interface [1]. Composites are generally a combination of numerous materials that are dissimilar in nature and they provide some resultant desired properties which are better than previous or parental ones. Natural fibers [2] are less dense, inexpensive, easily available, have good rusting resistive properties, abundant, nontoxic and not harmful to human skin, eyes and the respiratory system [3]. These renewable fibers are blended with polymers (matrix) to produce a new class of composites that are known as "green composites". Green composites [4] are lighter in weight and show excellent structural applications. If the matrix and the reinforcement are both made up of biodegradable [5] elements than the composite is known as a green composite, i.e. a specific class of biodegradable [6], [2] composites. In green composites 100\% degradation of the matrix and fiber occurs, while disposing the materials by burial. Green composites will reduce the ecological risk and improve the environment by reducing hazards due to non-degradable elements. Green composites have advantage that they usually end up within 50 days in landfill [7].

Soy protein isolate (SPI) films have low fragrance and $\mathrm{O}_{2}$ permeability so they are best suited for packaging industries making them suitable for products that are sensitive to the oxygen and for preserving flavors. SPI [8], [9], [10] has a hydrophilic nature because of the presence of $58 \%$ polar amino acids so it is impossible to remove moisture absorption but it can be reduced by applying chitosan coating on fabricated samples. Chitosan coating reduces moisture and water uptake. SPI contains more than $90 \%$ protein, SPI has $5 \%$ moisture, $4 \%$ fat and $5 \%$ ash and it is a commercial form of soy protein. They are renewable and eco-friendly in nature and are easily available which is the reason behind the growing interest in using SPI in packaging applications. A polymer generally used as a matrix because of its lower tooling cost, abundance, easy availability, being lighter in weight, being easy to manufacture and being less dense. SPI [11], [12], [13] was used as a matrix because it contains more than $90 \%$ protein and SPI has a better film making ability than other compunds such as fat-based ones. The $\mathrm{pH}$ value [14] has a significant effect on the film making ability of soy protein and it has been shown that near the isoelectric point ( $\mathrm{pH} 4.5$ ) soy protein could not make film due to coagulation [15]. These soy protein-based 
composites [16], [17] have numerous applications in the packaging, aviation, transportation and automobile industries, for use under water and in interior decoration.

\section{Materials and methods}

\subsection{Material}

The materials required for SPI-based green composites are SPI, phytagel, glycerol, sodium hydroxide $(\mathrm{NaOH})$ and human hair. SPI was brought from Nutrimed (India) and used as a resin because SPI contains $90 \%$ protein, $5 \%$ moisture, $4 \%$ fat and $5 \%$ ash and the protein has a better film making ability than fat, etc. Glycerol was used as a plasticizer and was included to improve ductility and was purchased from FM/s Allied Business Ltd. (India). Phytagel was purchased from Sigma-Aldrich Ltd. (USA) and was blended with SPI to establish an interpenetrating polymer network (IPN) that helps to improve the strength of the matrix. $\mathrm{NaOH}$ was purchased from M/s Allied Business Ltd. (India) and used for the alkali treatment of human hair fibers. Chitosan was purchased from Sigma-Aldrich (USA) and was applied on final sample to improve water uptake.

\subsection{Methods}

\subsubsection{Alkaline treatment}

Alkaline treatment of human hair fibers was done to improve the surface roughness of human hair fiber so that fiber made a strong bond with matrix material and as a result better properties and strong interfacial bonds were achieved. This treatment also removed dust, dirt, oil, wax and impurities from the surface of human hair fibers. For alkaline treatment, first human hairs were washed several times with fresh water to remove dirt and impurities from the surface and then dipped into $5 \% \mathrm{NaOH}$ solution for $2 \mathrm{~h}$ at $28^{\circ} \mathrm{C}$. The human hair fibers were then dipped into distilled water containing $1 \%$ acetic acid. Acetic acid was used to neutralize the remaining $\mathrm{NaOH}$ in the human hair [18], [19], [20] fibers and finally the fibers were washed multiple times with distilled water and oven dried at $70^{\circ} \mathrm{C}$.

\subsubsection{Fabrication of modify soy protein composite}

First, SPI was dissolved 20 times $(\mathrm{w} / \mathrm{w})$ in distilled water on the magnetic stirrer and after complete dissolution of SPI, $12.5 \mathrm{wt} . \%$ glycerol and $40 \mathrm{wt} . \%$ phytagel [21], [22] were added to that solution [21]. This mixture was kept on the stirrer at $70^{\circ} \mathrm{C}$ for $1 \mathrm{~h}$ and then after the appropriate measurement of wt.\% of human hair fibers, fibers were added to the solution and then poured on a galvanized iron sheet to be cooled in the oven at $40^{\circ} \mathrm{C}$ for approximately $24 \mathrm{~h}$ and before this greasing element had been applied on mold box to avoid the final product sticking in the mold box. Finally, the obtained composite was hot pressed in a compression molding machine at $80^{\circ} \mathrm{C}$ for $2 \mathrm{~h}$ at $25 \mathrm{~kg} / \mathrm{cm}^{2}$. Similarly, all samples with the same resin or matrix were made but each time weight $\%$ of human hair varied as $0,1,2,3,5,7$ and $10 \mathrm{wt} . \%$. Table 1 represents the nomenclature of the different fabricated composites.

Table 1: Compositions of different wt.\% of human hair $(\mathrm{HH})$ reinforced SPI composites.

\begin{tabular}{|c|c|c|c|}
\hline $\begin{array}{l}\text { Designation of } \\
\text { composition }\end{array}$ & SPI resin (wt.\%) & $\begin{array}{r}\text { Composition (wt.\% of soy } \\
\text { protein isolate resin) }\end{array}$ & wt. $\%$ of human hair \\
\hline $0 \% \mathrm{HH}$ & 100 & $\begin{array}{r}12.5 \text { wt. } \% \text { of glycerol }+40 \\
\text { wt. } \% \text { of phytagel }\end{array}$ & 0 \\
\hline $1 \% \mathrm{HH}$ & 100 & $\begin{array}{r}12.5 \text { wt. } \% \text { of glycerol }+40 \\
\text { wt. } \% \text { of phytagel }\end{array}$ & 1 \\
\hline $2 \% \mathrm{HH}$ & 100 & $\begin{array}{r}12.5 \text { wt. } \% \text { of glycerol }+40 \\
\text { wt. } \% \text { of phytagel }\end{array}$ & 2 \\
\hline $3 \% \mathrm{HH}$ & 100 & $\begin{array}{r}12.5 \text { wt. } \% \text { of glycerol }+40 \\
\text { wt. } \% \text { of phytagel }\end{array}$ & 3 \\
\hline $5 \% \mathrm{HH}$ & 100 & $\begin{array}{r}12.5 \text { wt. } \% \text { of glycerol }+40 \\
\text { wt. } \% \text { of phytagel }\end{array}$ & 5 \\
\hline
\end{tabular}




\subsubsection{Chitosan coating}

The chitosan solution was prepared by dissolving $0.2 \mathrm{~g}$ of chitosan flakes in $100 \mathrm{~mL}$ of acetic acid solution (1\%, $\mathrm{v} / \mathrm{v}$ ) and the solution was then kept on the magnetic stirrer for $2 \mathrm{~h}$ at room temperature [4]. Already fabricated samples were kept in an oven at $60^{\circ} \mathrm{C}$ for $2 \mathrm{~h}$ to evaporate the moisture before coating them and afterward samples were dipped into chitosan solution for $2 \mathrm{~min}$, then samples were dried at room temperature for $24 \mathrm{~h}$.

\subsection{Scanning electron microscopy}

A scanning electron microscopy (SEM) study was done to see the distribution of human hair fibers in the SPI resin-based green composites. The images were achieved through microscopic inquiry with the model JSM6610LV. Gold coating was done using a model JFC 1600. To acquire the scanning electron micrographs of each percentage sample, the fractured surface of tensile specimen was taken into consideration.

\subsection{Mechanical testing}

Tensile tests were used to determine the Young's modulus, elongation and ultimate tensile strength. The tests were conducted on $25 \mathrm{KN}$ servo hydraulic UTM machine (model AMT-SC). The crosshead speed was taken as $1 \mathrm{~mm} / \mathrm{min}$. All tests were conducted at $29^{\circ} \mathrm{C}$ and the relative humidity (RH) was $67 \%$. All the samples for tensile testing were prepared according to the ASTM D 638 type IV standards.

\subsection{Water uptake test}

Firstly samples were dried in an oven and then submerged in water at $29^{\circ} \mathrm{C}$. To decide the rate of water absorption, the readings were being taken every $10 \mathrm{~min}$ for a total time period of $120 \mathrm{~min}$. Their final weight $\left(\mathrm{W}_{2}\right)$ was calculated with the help of an electronic weighing machine while initial weight was $\left(\mathrm{W}_{1}\right)$ and percentage water absorption was obtained from equation (1).

$$
\text { Water uptake }(\%)=\frac{\left(\mathrm{W}_{2}-\mathrm{W}_{1}\right)}{\mathrm{W}_{1}} \times 100
$$

\subsection{Dynamic mechanical analysis}

Dynamic mechanical analysis (DMA) is used to determine the dynamic mechanical properties such as the glass transition temperature and storage modulus of the composite material using a DMA analyzer (7100 HITACHI). For DMA, specimens were cut into size of $40 \mathrm{~mm} \times 10 \mathrm{~mm}$ and the tests were performed in tensile mode at 1 $\mathrm{Hz}$ frequency in the temperature range of $27^{\circ} \mathrm{C}$ to $220^{\circ} \mathrm{C}$ at the rate of $5^{\circ} \mathrm{C} / \mathrm{min}$.

\section{Results and discussion}

\subsection{Morphology}

Figure 1A shows the neat SPI matrix which contains 40 wt. $\%$ phytagel and 12.5 wt. $\%$ glycerol. Figure $1 \mathrm{~B}$ shows the fracture surface of a $1 \mathrm{wt} . \%$ human hair reinforced SPI resin, the human hair composition was very less which results in good interaction between human hair fiber and SPI resin-based matrix. Proper bonding and 
development of non-uniform composition gave relatively high strength. At 2 wt.\% of human hair good interfacial bonds were formed between the fiber and the matrix so the load is properly transfered to fiber results in an improvement in the mechanical properties as shown in Figure 1C. At 3 wt.\% of human hair, the failure mechanism is due to the crack growth which leads to the splitting of human hair from the surface, due to which decrement in tensile strength had been noticed. At a lower concentration of human hair fiber having a strong bond with the matrix and first crack were initiated in the matrix, then in the fiber and followed-up by debonding of the matrix interphases, followed by another fiber failure and so on leading to whole composite failure and the matrix became unstable and matrix-fiber debonding at $3 \mathrm{wt} . \%$ of human hair was observed as shown in Figure 1D. As human hair fiber increased to $5 \mathrm{wt}$.\% of human hair, the tensile strength was decreased because at higher percentage cracks, voids and fiber pull-off problems were encountered as shown in Figure 1E. As human hair is hydrophobic in nature and the SPI resin is hydrophilic in nature, they began to repel each other and a weak interfacial bond was formed between fibers and the matrix. Human hair has a smooth surface so sliding between fiber and matrix occurs as is shown in Figure 1E. Failure occurred due to fiber pull-off and the fiber breaking simultaneously and sometimes the interaction between human hair fiber and the matrix became very poor or all the human hair began making clusters or all the human hair fibers did not get chance to interact and a make bond with the SPI-based resin which resulted in reduced tensile strength.
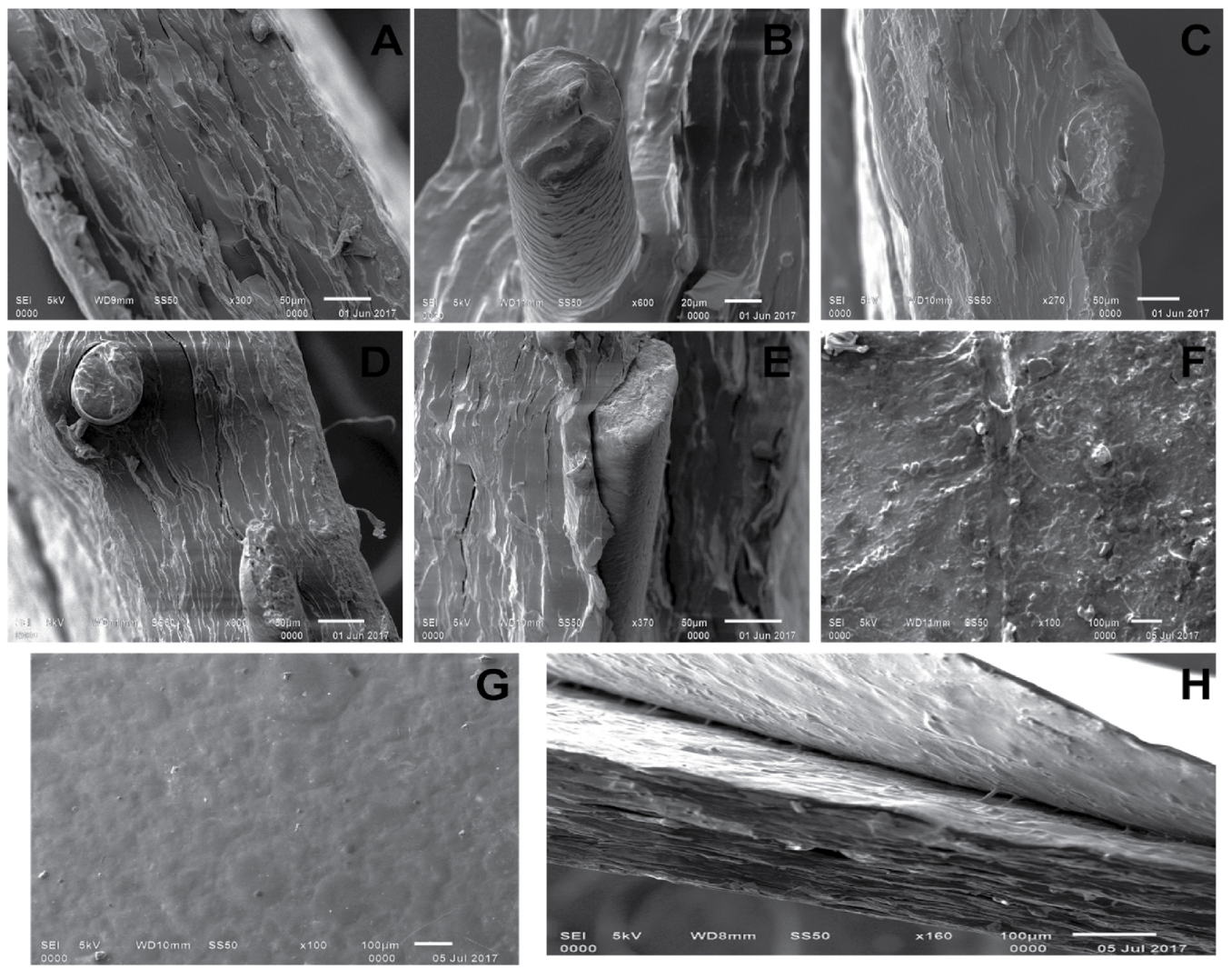

Figure 1: SEM image of SPI-based blend films (A) 0 wt.\% human hair, (B) 1 wt.\% human hair, (C) 2 wt.\% human hair, (D) 3 wt.\% human hair, (E) 5 wt.\% human hair, (F) non-coated surface of SPI composite, (G) coated surface of SPI composites and (I) chitosan coated surface making adhesive bonding.

Non-coated composites had a comparatively poor surface finish but after application of chitosan coating, surface voids and surface cracks were filled with chitosan and the surface became smoother than non-coated surface. The tensile strength improved in the case of chitosan coated composites due to low stress concentration on the coated surface. The chitosan coating did not change the composition of the basic matrix and remained on surface of composites and made adhesive bonds.

\subsection{Mechanical properties}

As per the SEM images at $1 \mathrm{wt} . \%$ of human hair, good interfacial bonds were formed between human hair fibers and the SPI-based matrix and gave relatively high tensile strength. At $2 \mathrm{wt} . \%$ of human hair, the magnitude of the load transferred to the human hair fiber was more as compared to matrix and as the contribution of fiber increased, the resultant tensile strength was also improved. This was supported by the occurrence of proper 
fiber breakage. At 3 wt.\% of human hair debonding was observed and the matrix became unstable and tensile strength began to dcreasee as shown in Table 2. At $5 \mathrm{wt} . \%$ human hair fiber pull and voids problems were encountered and this happened because the matrix is hydrophilic in nature and human hair is hydrophobic in nature so they began to repel each other which resulted in the poor holding capacity of the matrix for human hair. At higher wt.\%, human hair fibers began to accumulate and each fiber did not get chance to make bond with matrix result in shear failure due which low tensile strength obtained as shown in Figure 2A. Chitosan coating on the final samples improved the tensile strength as shown in Figure 2B of the resultant composites. By the application of chitosan coating on the samples, surface voids and surface cracks were filled with chitosan coating solution and a comparatively smoother surface was obtained. As the surface became smoother than non-coated samples, surface roughness was reduced and the stress concentration value was also reduced and finally, an increment in tensile strength was noticed.

Table 2: Tensile properties coated and non-coated SPI resin reinforced with human hair.

\begin{tabular}{|c|c|c|c|c|}
\hline \multirow[t]{2}{*}{ Human hair (wt.\%) } & \multicolumn{2}{|c|}{ Ultimate tensile strength (MPa) } & \multicolumn{2}{|c|}{ Elongation (\%) } \\
\hline & Coated & Non-coated & Coated & Non-coated \\
\hline 0 & 11.67 & 8.54 & 25.39 & 28 \\
\hline 1 & 21.88 & 14.58 & 20.77 & 23.37 \\
\hline 2 & 24.54 & 17.23 & 15.42 & 19.99 \\
\hline 3 & 18.18 & 14.18 & 13.25 & 15.5 \\
\hline 5 & 17.12 & 13.45 & 12.33 & 13.37 \\
\hline 7 & 15.70 & 12.24 & 11.18 & 12.42 \\
\hline 10 & 13.8 & 11.72 & 8.7 & 11.05 \\
\hline
\end{tabular}
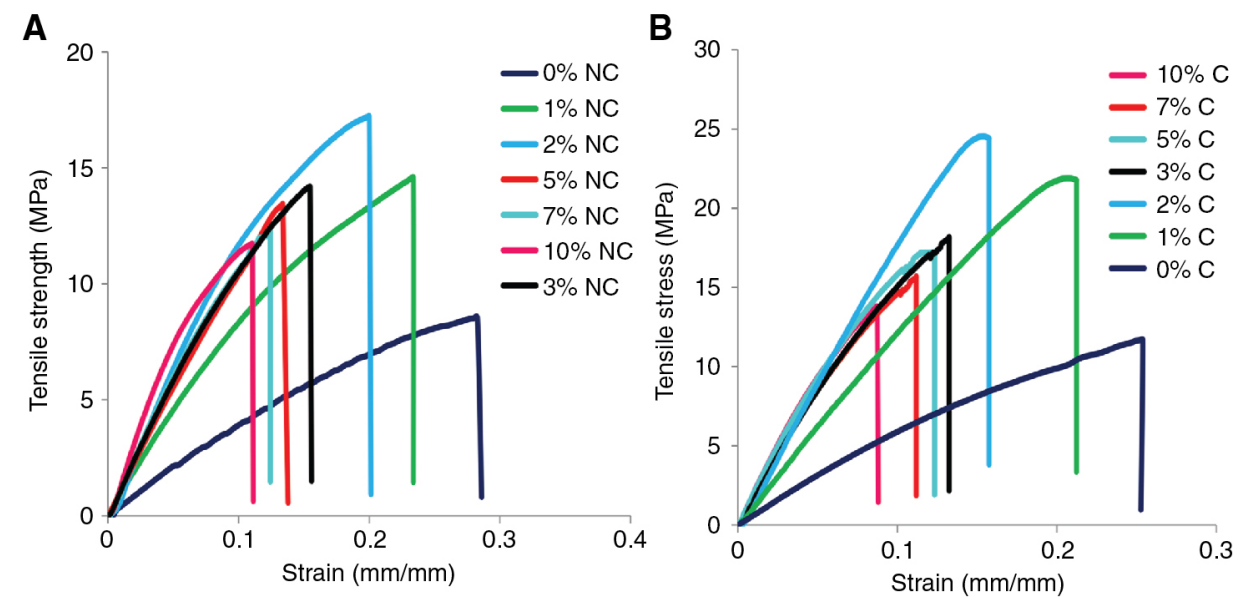

Figure 2: Tensile stress-strain diagram for human hair reinforced phytagel modified SPI composite (A) non-coated and (B) coated.

\subsection{Water uptake test}

In the first $20 \mathrm{~min}$ the water absorption rate was high due to the presence of voids in the final composite because water filled these voids. After $20 \mathrm{~min}$, the rate of water absorption as shown in Figure 3 decreased as all the voids present in the composite sample were already filled with water. Finally beyond $70 \mathrm{~min}$ the water absorption rate became constant. With the increment in human hair fibers wt.\%, the water absorption rate was increased because at a lower wt.\% of human hair there was good bonding between the fiber and the matrix so the number of voids are less and the surface area exposed to water while it dipped into a water beaker would be less. However, at higher wt.\% of human hair the number of voids and cracks were high because of poor bonding and holding between the human hair fiber and the matrix, so \% water absorption would be less at a lower wt.\% of human hair composition. 
A

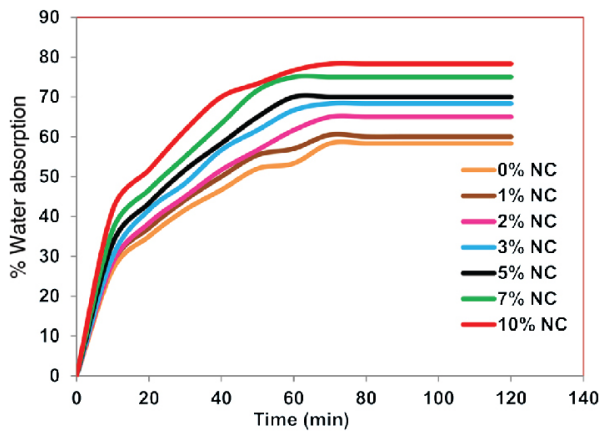

B

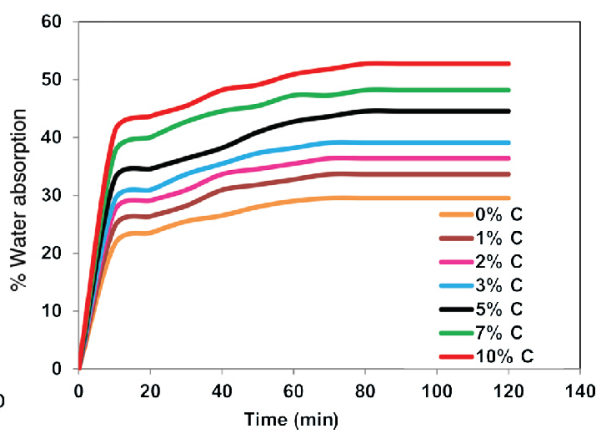

Figure 3: Water absorption for (A) non-coated and (B) coated bio-composites.

Figure 3B shows there was three zones; the first zone was from 0 to $10 \mathrm{~min}$, the second zone was from 10 to $60 \mathrm{~min}$ and the third zone was beyond $60 \mathrm{~min}$. Due to the chitosan coating the water absorption rate was decreased because most of the voids and surface crack were filled with the chitosan solution so the surface area exposed to water was reduced as compared to non-coated surface while we dipped samples into water for certain intervals of time. In first $10 \mathrm{~min}$ the water absorption rate was high due to the presence of voids in the final composite because water filled these voids but most of the voids had been filled with chitosan coating solution so the water absorption rate decreased by considerable amount as compared to non-coated composites and for next 50-60 min there was reduction in the rate of water absorption and afterward the rate of water absorption became almost constant or steady.

\subsection{Dynamic mechanical analysis}

As shown in Figure 4, at 1 wt.\% of human hair the interfacial bonding between human hair and the SPI resin was comparatively good, the mobility of protein polymer chain was restricted and this resulted in decrement in the flexibility of the protein chain or the stiffness of the resultant composite had been improved therefore the storage modulus also improved. At $2 \mathrm{wt} . \%$ of human hair better interfacial bonds and maximum contribution of fibers were observed therefore the mobility of the SPI protein chain reduces because the proteins have long chain polymer structures that have a tendency to slide over one other. But with the incorporation of human hair interlocking was observed and as a result the stiffness of the resultant composite was improved and finally this gave the highest storage modulus at $2 \mathrm{wt} . \%$ of human hair. From 3 to $5 \mathrm{wt} . \%$ of human hair, as the wt. $\%$ of human hair increased, due to the hydrophilic nature of the matrix and and the hydrophobic nature of human hair they began to repel each other and this resulted in poor holding capacity of the fiber by the matrix. Due to the poor bonding between human hair fiber and the SPI resin this increased the mobility and flexibility of the SPI protein chain observed because SPIs have long chain polymer structures that slide over each other therefore the storage modulus value decreased as can be seen in Figure 3A. The neat SPI-based green composite exhibited maximum mobility so the storage value obtained was also less. 



C

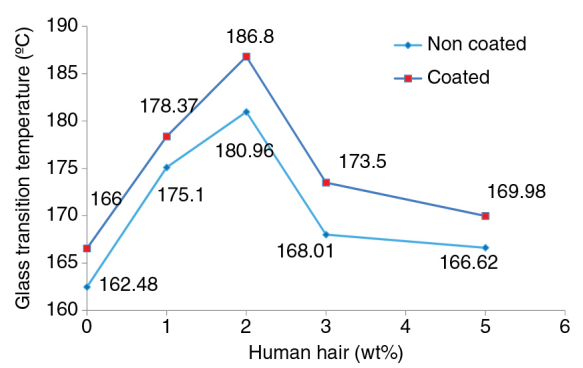

Figure 4: Result of dynamic mechanical analysis (A) storage modulus (B) tan $\delta$ and (C) glass transition temperature.

Due to the chitosan coating application on the final composites the stiffness of the fabricated samples was improved so the storage value of the coated samples at different compositions of human hair fibers was improved as is shown in Figure 3A.

Figure $3 \mathrm{C}$ shows that at $2 \mathrm{wt} . \%$ of human hair the glass transition temperature was higher than the rest and with the application of chitosan coating the glass transition temperature of respective samples had been improved. Figure 3B shows that the damping characteristics of $0 \mathrm{wt} . \%$ of human hair were highest so this can be used as a vibration absorber and at $2 \mathrm{wt} . \%$ of human hair damping characteristics was low so the energy dissipation rate would be less as $\tan \delta$ is a ratio of loss modulus to storage modulus.The peak of $\tan \delta$ is known as the glass transition temperature. At $1 \mathrm{wt} . \%$ human hair the interfacial bonding between human hair and the SPI resin was comparatively good and decrement in flexibility and the storage modulus of protein chain or $\tan \delta$ reduced and an improvement in glass transition temperature was observed. At $2 \mathrm{wt} . \%$ of human hair, better interfacial bonds were observed and the fibers were distributed at an optimum distance. This results in the mobility of the SPI protein chain being reduced because the fibers were interlocked with the protein polymer chain. The restriction in protein chain results in improvent in the glass transition temperature and storage modulus. As the human hair composition increased from 3 to $5 \mathrm{wt} . \%$ of human hair, poor bonding and interactions between fibers and the matrix were observed and the high mobility of the SPI protein chain was observed and $\tan \delta$ increased and glass transition temperature also reduced.

The $\tan \delta$ (internal fraction or damping fraction) is a ratio of loss modulus to storage modulus and also a function of temperature. A non-coated surface has many cracks and voids but while chitosan coating fills all voids and surface cracks of the surface of resultant composite. The energy dissipation mechanism was not applicable here and composites began acting like a brittle material which increases stiffness and storage modulus. This result in lower $\tan \delta$ value.

\section{Conclusions}

A human hair reinforced soy protein-based green composite was fabricated using a compression molding process with alkali treatment on the human hair fiber surface to increase surface roughness of the human hair fiber to improve the fiber and matrix interfacial bonding. Two wt.\% human hair gave the optimum results of the tensile test, i.e. 17.23 MPa and with the application of chitosan coating the tensile stress was improved to 24.54 MPa because the maximum surface cracks and voids were filled with the chitosan solution so the stress concentration reduced. Water absorption increased with the increment in human hair fiber wt.\% but chitosan 
coating reduced the water sensitivity. DMA test results showed that at $2 \mathrm{wt} . \%$ human hair storage modulus had the highest value but the lowest value of $\tan \delta$. SPIs have numerous applications in packaging, coating and other different fields. Chitosan coating improved the tensile strength, storage modulus and the glass transition temperature.

\section{References}

[1] CallisterWD. Materials Science and Engineering, 2nd edition. New York City, United States: ]ohn Wiley and Sons, 2015.

[2] Jain N, Singh VK, Chauhan S. J. Mech. Behav. Mater. 2018, 5-6, 205-211.

[3] Ramesh M, Palanikumar K, Reddy KH. Renew. Sust. Energ. Rev. 2017, 79, 558-584.

[4] Cynthia GFH, Arturo CC, Carlos VS, Victor MC, Jose LRA, Armando AC, Perla ECC, Ana LMH. Polymer 2014, 6, 686-705.

[5] Mitra BC. Def. Sci. J. 2014, 64, 244-261.

[6] Jain N, Singh VK, Chauhan S. J. Mech. Behav. Mater. 2018, 5-6, 213-222.

[7] Felix M, Martín-Alfonso JE, Romero A, Guerrero A. J. Food Eng. 2014, 125, 7-16.

[8] Rhim JW, Cennadios A, Weller CL, Hanna MA. Ind. Crops Prod. 2002, 15, 199-205.

[9] Routray M, Rout SN, Mohanty CC, Nayak PL. J. Chem. Pharm. Res. 2013, 5, 752-761.

[10] Song F, Tang D], Wang XL, Wang YZ. Biomacromolecules 2011, 12, 3369-3380.

[11] Behera AK, Avancha S, Basak RK, Sen R, Adhikari B. Carbohydr. Polym. 2012, 88, 329-335.

[12] Cao N, Fu YH, He JH. Food Hydrocoll. 2007, 21, 1153-1162.

[13] Chabba S, Netravali AN. JSME Int. J., Ser. A 2004, 47, 556-560.

[14] Cennadios A, Brandenburg AH, Weller CL, Testin RF. J. Agric. Food Chem. 1993, 41, 1835-1839.

[15] Kim JT, Netravali AN. Compos. Sci. Technol. 2011, 71, 541-547.

[16] Reddy N, Yang Y. Ind. Crops Prod. 2011, 33, 35-41.

[17] Zhang ], Jane ]. Polymer 2001, 42, 2569-2578.

[18] Choudhry, S, Pandey, B. Int. ]. Manage. Educ. 2012, 2, 118-121.

[19] Dankers LM. Physical Analysis of Human Hair. Master's Thesis, 6772. University of Missouri-Rolla, 2007.

[20] Gupta A. Int. J. Refract. Met. Hard Mater. 2009, 892-899.

[21] Lodha P, Netravali AN. Polym. Compos. 2005, 26, 647-659.

[22] Huang X, Netravali AN. Biomacromolecules 2006, 7, 2783-2789. 